\title{
POR QUE ENSINO COMO ENSINO? CONTEXTOS E NARRATIVAS DA TRAJETÓRIA DE UM PROFESSOR FORMADOR DE PROFESSORES
}

F. J. de Lima ${ }^{1}$

Instituto Federal do Ceará

franciscojose@ifce.edu.br

Submetido 14/08/2017 - Aceito 25/02/2018

DOI: $10.15628 /$ holos.2018.6217

\section{RESUMO}

Este ensaio apresenta reflexões a respeito da trajetória docente, reunindo fundamentos para pensar por que ensino como ensino, destacando os fios condutores de uma caminhada, apresentando contextos e narrativas que compreendem desde a formação inicial e atuação no magistério a atuação como professor formador de professores de matemática no IFCE campus de Cedro. Fundamentado em autores que dialogam sobre a formação de professores e suas necessidades formativas, Gòmez (1992), Zeichner (1993), Schnetzler (2000), Contreras (2002), Tardif (2002) foi possível pensar sobre a docência como espaço de aprendizagem e atuação profissional do professor, os quais exigem atenção frente às demandas da atualidade. Faz-se necessário (re)pensar a formação de professores na perspectiva da racionalidade prática, como espaço de ação e campo de aprendizagem contínua da docência, onde o professor formador deve trabalhar partindo da análise da prática docente para compreender os mecanismos e dispositivos mobilizados pelo professor durante sua ação profissional, examinando o que faz, por que o faz e como pode transformar o que faz(re) construindo-se continuamente.

PALAVRAS-CHAVE: aprendizagem da docência, docência, professor formador, ensino.

\section{WHY TEACHING AS TEACHING? CONTEXTS AND NARRATIVES OF THE TRAJECTORY OF A TEACHER TRAINER OF TEACHERS ABSTRACT}

This essay presents reflections about the teaching career, gathering grounds for wondering why teaching as teaching, highlighting the leads a walk, showing contexts and narratives ranging initial training and experience in teaching the teacher acting as a trainer of teachers of mathematics at IFCE Cedro campus. Based on authors who talk about the training of teachers and their training needs, Gòmez (1992), Zeichner (1993), Schnetzler (2000), Contreras (2002), Tardif (2002) it was possible to think about teaching as learning space and professional experience of the teacher, which require attention to today's demands. It is necessary to thinking about the training of teachers in the perspective of practical rationality, as a space for action and continuous learning field of teaching where the teacher trainer must work starting from the analysis of the teaching practice to understand the mechanisms and devices deployed by the teacher during your professional action, examining what it does, why does and how it can transform what does building continuously. 


\section{INTRODUÇÃO}

Reporta-se a trajetória profissional e aos condicionantes que influenciaram ou não na formação da identidade do professor, exige um enorme reforço para resgatar elementos que se encontram no passado. É bem verdade que esses elementos podem aparecer em ações da prática docente cheios de intencionalidade, bem como, se encontram imersos em contextos e narrativas vividos pelo professor que invariavelmente tem sua prática baseada em referenciais pedagógicos que julgam adequados para o exercício da docência, os quais decorrem de sua formação inicial, de experiências com colegas e de sua própria experiência.

Este artigo propõe-se refletir a respeito da prática pedagógica buscando fundamentos para pensar por que ensino como ensino. Para isso, procura-se tecer os fios que conduziram a caminhada profissional, da formação inicial aos primeiros anos de atuação no magistério, destacando a sala de aula como espaço capaz de propiciar a aprendizagem da docência, sendo um local de referência para a formação continuada, no qual se pode dialogar continuamente sobre o fazer do professor diante das demandas atuais. Apoiando-se em autores que discutem a formação de professores e suas necessidades formativas, tais como Gòmez (1992), Zeichner (1993), Schnetzler (2000), Contreras (2002), Tardif (2002) foi possível pensar sobre a minha trajetória docente e, principalmente, meu fazer pedagógico como professor formador de professores para o ensino de matemática.

A atuação profissional e o envolvimento com a formação de professores se constituem como espaço/tempo compreendido por aprendizagem contínua e pressupõe o contato com diferentes saberes, experiências e alternativas metodológicas, os quais podem desencadear melhorias na prática de ensino do professor, merecendo atenção à reflexão sobre a própria experiência, se fazendo necessário reconhecer que aprender a ensinar se prolonga durante toda a carreira do professor.

Desta forma, a passagem por diferentes contextos permitiram o desencadeamento de narrativas que se apresentam as contribuições para a construção da identidade profissional docente, evidenciando a atuação como professor formador de professores de matemática no IFCE campus de Cedro. Esta prática tem se sustentado na tentativa de contribuir com a formação inicial de professores para o ensino de matemática, que sejam capazes de articular teoria e prática, objetivando investigação para resolver problemas educacionais, melhorar a prática pedagógica e o desenvolvimento profissional do professor.

Portanto, pensar sobre a própria atuação profissional, principalmente, porque ensino como ensino, exige um exercício de reflexão tamanho acerca de minha existência e dos anos iniciais de efetivo trabalho na docência. A partir da produção de cada linha, de cada parágrafo, se revela aos poucos os traços de uma trajetória constituída de história, de desafios, de medos, de incertezas e de momentos que precisam ser enaltecidos por expressarem desejo de mudança, superação e aprendizagem contínua. 


\section{DA FORMAÇÃO AOS ANOS INICIAIS DE PRÁTICA DOCENTE}

No Brasil, em um passado não muito distante, a habilitação para o exercício da docência era obtida no 2 o grau magistério. A Lei no 5.692, de 11 de agosto de 1971 que fixava as diretrizes e bases para o ensino de 10 e 20 graus assegurava em seu Art. 30 que a exigência mínima para o exercício do magistério no ensino de $1 \underline{0}$ grau, da 1 a à $4^{a}$ série do ensino fundamental, era habilitação específica de $2 \stackrel{\circ}{\circ}$ grau.

A formação em magistério (Nível Médio) "sancionada por um diploma que possibilita o acesso a um título profissional, [...] que protege um determinado território contra a invasão dos não-diplomados e de outros profissionais" (TRADIF, 2002, p.247) me permitiu ingressar na docência e assumir responsabilidades grandiosas, as quais se fizeram desvinculadas de reflexões sobre o significado da atividade docente; a importância do trabalho do professor para o desenvolvimento de uma nação; a necessidade de seu reconhecimento público; bem como o impacto de sua atuação pedagógica na formação de sujeitos ativos e conscientes para a mudança do contexto no qual se encontram inseridos.

A ausência de reflexão crítica sobre os pontos apresentados anteriormente se confundiram com a necessidade de sobrevivência e a oportunidade da primeira atividade remunerada em uma comunidade basicamente agrícola, não assalariada. O convite para lecionar no ensino básico se constituiu como alternativa para ingressar no mundo trabalho.

Era o ano de 1997, precisamente 03 de fevereiro. Naquela data se iniciava o ano letivo e o meu ingresso no magistério, como professor contratado para lecionar em uma turma da 5a série, no turno manhã da Escola de 10 grau João Batista Moreno, a qual era subordinada à secretaria de educação da cidade de Cedro, estado do Ceará. Para iniciar as atividades docentes a Secretaria de Educação Municipal em parceria com a Coordenadoria de Desenvolvimento da Educação Básica do Estado (CREDE 17) promoveu um curso preparatório de 40 horas/aula para os professores contratados. O curso se concentrou em "ajudar os professores a imitarem melhor as práticas sugeridas por investigações que outros conduziram e negligenciam-se as teorias e saberes implantados tanto nas suas práticas como nas de outros professores" (ZEICHNER, 1992, p.22).

Passado o primeiro semestre, fui convidado para substituir uma docente que havia se aposentado, na turma da 3a série, do turno tarde da Escola de 1으 Francisco Silveira Aguiar da rede estadual de ensino. No final do ano de 1997 me tornei professor efetivo do município, com 20 horas aula semanais, por meio de concurso público de provas e títulos promovido pela prefeitura para o provimento de vagas no magistério municipal. Como o número de aprovados no concurso público de 1997 foi insuficiente, no ano de 1998 a prefeitura promoveu mais um concurso público de provas e títulos para professor. Com a aprovação no certame, me tornei professor efetivo da rede municipal com 40 horas aulas semanais.

Naquele contexto, final da década de 1990 se acreditava que para exercer a docência eficazmente, bastava dominar os conteúdos e administrar os conflitos e embates surgidos no 
cotidiano da sala de aula. Essa ideia era fortalecida em assembleias da Associação de Pais e Comunitários (APC) e nas reuniões pedagógicas promovidas pela escola.

O modelo da racionalidade técnica que se originou da força da ciência se encontrava bastante arraigado no fazer institucional, onde "a atividade profissional é, sobretudo instrumental, dirigida para a solução de problemas mediante a aplicação rigorosa de teorias e técnicas científicas" (GÓMEZ, 1992, p.98).

Embora tivesse concluído o curso pedagógico em nível médio, cuja formação era calcada no estudo elementar de teorias e escassa evidência de atividades práticas, os quais não passavam de observações e participações em sala de aula. A aprendizagem da docência foi se desenhando com as primeiras experiências que se constituíram de tensões, incertezas, medos e o desafio de aprender a docência a partir dos erros e acertos alcançados no decorrer de ações pedagógicas realizadas. Assim, o fazer docente resulta em experiências que se constituem em saberes. A esse respeito, Tardif (2002, p.49) assegura que são saberes que

[...] não se encontram sistematizados em doutrinas ou teorias. São saberes práticos (e não da prática: eles não se superpõem à prática para melhor conhecêla, mas se integram a ela e dela são partes constituintes enquanto prática docente) e formam um conjunto de representações a partir das quais os professores interpretam, compreendem e orientam sua profissão e sua prática cotidiana em todas as suas dimensões. Eles constituem, por assim dizer, a cultura da ação docente.

A ação docente cotidiana permite ao professor lidar com os limites e as possibilidades da profissão no contexto onde esta, está sendo exercida, não excluindo as condições de trabalho que pode se configurar como fator de sucesso ou insucesso da prática profissional e, consequentemente, da aprendizagem da docência a partir do exercício da profissão, compreendendo que toda prática docente manifesta crenças, valores e concepções sobre o mundo, o ser humano, a escola e o processo de ensino-aprendizagem.

Tomando como referência as práticas de professores que tive durante o período da escolaridade básica, iniciei o meu percurso profissional tentando corresponder às expectativas da escola e da comunidade onde estava situado. Naquele contexto, professor bom era aquele transmitia o conteúdo com segurança e tinha moral, isto é, dominava a sala de aula.

A adesão por uma postura mais rígida em sala de aula foi influenciada por vivências do tempo de aluno, principalmente as recordações de professores que sabiam ensinar (Dominavam os conteúdos), que atuavam com rigidez (Mantinham a disciplina e a organização da sala de aula) que pegavam no pé dos alunos (Insistiam diariamente com os educandos por melhorias na aprendizagem) e que faziam coisas diferentes em sala de aula (Diversificavam a metodologia de ensino, eram criativos) predominaram. Entretanto, as lembranças de professores, cujas ações práticas se distanciaram dos aspectos mencionados acima, também contribuíram com a formação da minha identidade profissional, uma vez que, suas ações práticas mostraram o que não deveria ser feito em sala de aula. 
No primeiro ano atuando como professor, a prática pedagógica desenvolvida se condicionava a aspectos da pedagogia tradicional, definida como uma concepção portadora de costumes de séculos passados, como uma prática do saber-fazer conservadora, prescritiva e ritualista reprodutora do método conteudista de ensino, onde o autoritarismo era sinônimo de domínio frente aos alunos em sala de aula e a comunidade escolar. Neste cenário, traços da concepção de "educação bancária" (FREIRE, 1996) eram visíveis na ação docente, que inconscientemente ou preservando a cultura do controle existente na escola, o professor atuava como depositante e os alunos como receptores de conhecimentos curriculares.

Esta postura de atuação na escola, concebida sob a perspectiva do modelo da racionalidade técnica, se concentrava em modelos de práticas pedagógicas pré-estabelecidas para a aceitação do profissional em um determinado contexto sócio-cultural, onde o professor iniciante age por imitação na tentativa de conceber a escola como um espaço que deve "capacitar jovens para adquirir o conhecimento que, para a maioria deles, não pode ser adquirido em casa ou em sua comunidade" (YOUNG, 2007, p.1294).

Independente de concepções filosóficas ou pedagógicas, a aprendizagem dos alunos era o principal objetivo. No desejo de uma aprendizagem significativa, as aulas, em sua maioria, procuravam associar os conhecimentos curriculares à vida prática dos alunos, potencializando significado aos conteúdos estudados em sala de aula. Assim, o que importava de fato, era saber é se o trabalho docente desenvolvido ajudava os alunos a desenvolver uma atividade intelectual e qual o sentido dessa situação para os alunos (CHARLOT, 2002).

\section{A SALA DE AULA E A APRENDIZAGEM DA DOCÊNCIA}

A formação em nível superior aconteceu paralelamente ao exercício da docência na educação básica, face às exigências da Lei de Diretrizes e Bases da Educação Nacional - Lei no 9.394/96. No curso de pedagogia ficou fortemente evidenciado que o professor deve ser conhecedor do que se propõe ensinar para fazer a mediação pedagógica entre os processos de ensino e de aprendizagem, percebendo a diversidade e a heterogeneidade que constitui o universo da sala de aula como espaço de aprendizagem discente e docente.

No processo de formação inicial superior, a metodização de teorias da ciência da educação era fortemente incorporada ao modelo transmissão-recepção e apresentava certa desvinculação entre teoria e prática. Como expressa Tardif (2002, p. 23) "até agora, a formação para o magistério esteve dominada sobretudo pelos conhecimentos disciplinares, conhecimentos esses produzidos geralmente numa redoma de vidro, sem nenhuma conexão com a ação profissional".Na universidade a elevada quantidade de leituras, resumos, seminários e rodas de conversa eram usualmente trabalhos na perspectiva de munir os futuros professores de embasamento teórico para o exercício da docência.

Entre um texto e outro, eram oportunizadas reflexões acerca da aprendizagem da profissão, provocando o pensar sobre os desafios contidos na docência e seus condicionantes. Nas 
atividades em grupo, os participantes socializavam suas vivencias de sala de aula e externavam suas dificuldades e perspectivas em relação ao fazer docente na escola. Discussões sobre as condições, precarização do trabalho do professor e seus agravantes se destacavam como oportunidade de refletir sobre os elementos capazes de contribuir ou não, com os resultados da atividade docente. Mesmo assim, a formação se centrava no domínio do conteúdo a ser ensinado na prática, como tradição acadêmica de uma epistemologia dominante na universidade.

Os conhecimentos teóricos adquiridos na graduação e as experiências oriundas da prática em sala de aula permitiram depreender que a essência do trabalho docente consiste em o professor ter clareza do que ensinar aos alunos para despertar autonomia de pensamento, pois o processo de ensino-aprendizagem é um processo de enculturação, isto é, entrada no mundo da cultura. Assim, na escola, deve ser viabilizado acesso ao conhecimento poderoso que, por sua vez, pode "fornecer explicações confiáveis ou novas formas de se pensar a respeito do mundo" (YOUNG, 2007, p.1294).

A prática cotidiana se apresenta como um importante mecanismo que poderá contribuir com o desenvolvimento da aprendizagem da docência, pois na sala de aula "acontecem muito mais coisas do que se poderia prever e manipular em um esquema de relações entre ações educativas e efeitos pretendidos" (CONTRERAS, 2002, p.103). Assim, o exercício diário da profissão docente permite ao professor compreender que o modelo da racionalidade técnica não dar conta dos inúmeros problemas que surgem na sala de aula, como espaço nutrido por relações e nos contornos da escola e do trabalho docente.

Contrariamente à racionalidade técnica, o modelo da racionalidade prática propõe a superação existente na relação entre o conhecimento científico-técnico e a prática de sala de aula. Neste campo, o ponto de partida é a análise da prática docente para compreender os dispositivos mobilizados pelo professor durante sua ação profissional, o qual obterá êxito, conforme sua capacidade para conduzir a complexidade existente no processo de ensino-aprendizagem e na resolução de problemas práticos, por meio da integração entre conhecimento e técnica.

Acredito que é na sala de aula que experimentamos a necessidade contínua de dialogar com a nossa ação e, principalmente com os resultados obtidos a partir da ação como fundamento do nosso fazer. Como professor, ao vivenciar minhas experiências na prática, foi necessário muitas vezes repensá-las, redesenhá-las buscando alternativas para melhor ensinar. Hoje sei que o que fiz, mesmo sem compreender, foi problematizar minha prática, visto que não me contentava com o que vinha produzindo em meu fazer. A problematização e o descontentamento com as aparências impulsionavam para a efetivação do exercício do diálogo permanente, contribuindo para o desencadeamento do conhecimento poderoso do qual, o educando tem direito para melhor interpretar o mundo que o cerca. Conforme Contreras (2002, p.117-118) a docência pode,

[...] em grande medida, ser um hábito, uma construção pessoal de habilidades e recursos com os quais resolvemos nossa prática, mas que em determinados momentos somos capazes de torná-la consciente para aperfeiçoá-la. O processo de aperfeiçoamento profissional não se produz mediante a transmissão de 
teorias, mas questionando essas habilidades e recursos que refletem as capacidades pessoais com respeito à prática de ensino, ao conhecimento ministrado ou às pretensões educativas.

O aperfeiçoamento profissional docente como extensão necessária, deve ser movido por interrogações, pois quando o professor se contenta com respostas prontas, não caminha, não consegue problematizar, podendo potencializar escassez de espaço para (re)pensar o seu fazer pedagógico.

Neste processo de autotransformação as experiências poderão contribuir para o aprimoramento de práticas e para a efetivação de formação contínua, aprendizagem que pressupõe o contato com diferentes saberes, experiências e alternativas metodológicas, capazes de possibilitar melhorias no trabalho a ser desenvolvido em sala de aula, principalmente, no processo de ensino-aprendizagem. Além da aprendizagem da matéria a ser ensinada em sala de aula, o aperfeiçoamento profissional docente traz consigo aspectos relevantes que constituem o ser professor, pois

[...] ao conhecer a estrutura da disciplina em que se trabalha e ao refletir sobre o ecossistema peculiar da sala de aula, o professor não se limita a deliberar sobre os meios, separando-os da definição do problema e das metas desejáveis, antes constrói uma teoria adequada à singular situação do seu cenário e elabora uma estratégia de ação adequada. (GÓMEZ 1992, p.106)

Por isso, se acredita que o professor precisa ter domínio de sua área de atuação para desenvolver o processo de ensino-aprendizagem com significado e ter controle sobre a ação para propiciar ao educando o conhecimento poderoso.

\section{ENTRE A ATUAÇÃO PROFISSIONAL E O ENVOLVIMENTO COM A FORMAÇÃO DE PROFESSORES}

As primeiras aproximações com a formação de professores se deram a partir do momento em que assumi a administração de uma escola municipal de educação básica, na qual fui aluno e retornei como professor. Estando à frente da gestão escolar (2000 a 2003) e, posteriormente, da coordenação pedagógica (2004 a 2010), precisava, a partir da minha ação como gestor/coordenador, incentivar à necessária articulação entre teoria e prática no fazer pedagógico de professores que atuavam da educação infantil ao ensino fundamental.

O trabalho como gestor escolar ocorreu durante quatro anos e a experiência na área se concentrou, principalmente na administração institucional e responsabilidade social, ensino e aprendizagem, gestão de pessoas e o primado da convivência e da participação, gestão financeira e patrimonial e gestão democrática a ser vivenciada no cotidiano escolar.

Passados os quatro anos e não continuando na gestão geral da escola, iniciei o curso de Licenciatura em Matemática do Instituto Federal de Educação, Ciência e Tecnologia do Ceará (IFCE) campus de Cedro. Neste mesmo período, fui convidado para vivenciar a experiência de coordenador pedagógico, cujas atividades se concentravam na organização de momentos 
coletivos para elaboração, implementação, acompanhamento e avaliação da proposta pedagógica da escola, tentando garantir sua vivência prática, orientando pais e responsáveis, alunos, educadores e demais funcionários da instituição à manutenção das posturas pedagógicas definidas coletivamente.

A realização de planejamentos educacionais acontecia periodicamente, porém a ênfase na promoção do processo de ensino-aprendizagem era timidamente oportunizada, uma vez que, os encontros pedagógicos deveriam abordar a docência, a prática de ensino em sala de aula e os problemas a serem enfrentados pela comunidade escolar. Os encontros faziam parte da agenda de trabalho dos professores, eram amparados pelo Plano de Cargos e Carreira do Magistério Municipal e naquele momento era concebido como espaço de repasses da secretaria de educação e tempo para o preenchimento de fichas e diários de classe.

Por acreditar que a prática docente deve estar em contínuo processo de atualização, a escola como campo de atuação profissional do professor, deve propor e mobilizar os sujeitos para continuarem aprendendo a partir de seus contextos de atuação, voltando-se para suas práticas como referência, na tentativa de constante redimensionamento do fazer pedagógico. Diante disso, sugeri outro formado de encontro pedagógico, fundamentado na partilha e análise de experiências vividas pelos professores em suas salas de aula.

Com esta premissa, ao invés de repasses e preenchimento de fichas e diários de classe, os encontros pedagógicos passaram a ser pensados como oportunidade para analisar e refletir sobre a prática pedagógica e propiciar encaminhamentos para a formação de professores em contexto de trabalho, por meio de estudos, de discussões e de socialização de experiências, buscando (re)vitalizar abordagens e metodologias de ensino capazes de contribuir para o desempenho acadêmico dos alunos. Inicialmente, muitos professores resistiram, pois já estavam acostumados com aquele tipo trabalho e alegavam que discussão sobre a profissão não resolvia os problemas enfrentados no cotidiano escolar.

Com insistentes diálogos, realização efetiva dos encontros pedagógicos, temáticas abordadas, envolvimento e aceitação dos colegas, os professores acabaram reconhecendo de fato, que os encontros era um tempo reservado para refletir/aprender sobre a docência a partir das experiências vividas em sala de aula e compartilhadas em momentos coletivos. Alguns professores que exerciam a docência na escola em regime temporário que, posteriormente, participaram e foram aprovados em concurso para professor efetivo do município, afirmavam em depoimentos que os encontros pedagógicos realizados na escola se constituíam em espaço de aprendizagem e aperfeiçoamento contínuo da profissão docente.

Como a prática docente não é destituída de uma política, se torna oportuno refletir sobre a prática para entender os limites e as possibilidades do ensino, verificar as orientações curriculares, perceber os recursos didáticos disponíveis na escola e sua influência nas escolhas pedagógicas e investir na socialização e troca de experiências. Todos esses pressupostos devem caminhar rumo a novas aprendizagens, num exercício constante de prática construída colaborativamente, 
contribuindo com o desenvolvimento de indivíduos inseridos em uma sociedade acentuadamente caracterizada por mudanças.

Para Veiga \& D'ávila (2008, p. 137), “a sociedade contemporânea caracteriza-se pela indefinição de paradigmas, reflexo do consumo estimulado pelo capitalismo, pela evolução tecnológica e pela difusão da informação". Diante deste cenário, a educação é uma prática social imprescindível, pois, é nela que se concretiza a interação entre os sujeitos do processo de ensinoaprendizagem e a reflexão sobre os contextos sociais em que acontecem tais fenômenos, a fim de, atender às novas exigências sociais, sendo o professor protagonista indispensável na promoção do conhecimento poderoso para a formação de sujeitos que atuarão em diferentes contextos da sociedade.

\section{ATUAÇÃO DOCENTE COMO PROFESSOR FORMADOR DE PROFESSORES DE MATEMÁTICA NO IFCE CAMPUS DE CEDRO}

Quando pensamos ou nos indagamos sobre a nossa trajetória profissional, centralizamos nossas respostas na formação acadêmica, nos cursos realizados e na prática profissional, deixando de fora algo que consideramos sem importância, a nossa presença e intervenção no contexto onde nos encontramos inseridos. Reportar-se a nossa ação docente como professor formador de professores não é tão fácil quanto parece. A partir de concursos públicos (2006 e 2008) para selecionar professor substituto para atuar no núcleo de disciplinas pedagógicas do curso de Licenciatura em Matemática do IFCE campus de Cedro, no qual era aluno, iniciei meu percurso como professor formador de professores.

Penso que o trabalho com a formação de professores de matemática se constitui em uma atividade desafiadora, caracterizada pela boniteza da docência, pela precarização da profissão, pela falta de clareza sobre o profissional que se deseja formar, pela "forte marca da formação do bacharel, considerada de prestígio acadêmico e científico" (SCHNETZLER, 2000, p.14) e para qual demanda se forma um professor em contextos de mudanças e incertezas. Estas características potencializam atenção, pois "a investigação educativa tem se preocupado com os discursos e não com a realidade que flagra a realidade profissional na qual trabalham os professores e as suas condições de trabalho" (SACRISTÁN, 2002, p.84).

A tradição monodisciplinar caracteriza a universidade. Na contramão desta característica, o desafio consiste em contribuir para a formação de um profissional capaz de lidar com o processo de ensino-aprendizagem reelaborando pedagogicamente sua ação, a partir da prática, em função da aprendizagem matemática do aluno. No IFCE campus de Cedro se percebe que o ensino de matemática acaba centralizando seus esforços em disciplinas específicas, se configurando como um bacharelado e não como um curso de licenciatura capaz de possibilitar concessão para o exercício da docência em matemática.

Nos últimos 30 anos, o que mais temos encontrado na literatura disponível e acessível sobre formação docente em geral, e particularmente no âmbito das 
ciências naturais, são temas que configura problemas, que expressam constatações de que geralmente os professores têm sido mal formados e que, por isso, não são/estão preparados para darem "boas aulas" em qualquer dos níveis de escolaridade (SCHNETZLER, 2000, p.13)

Para a realização da atividade docente, se faz necessário o desenvolvimento de um conjunto de saberes que se nutrem do domínio de conhecimentos teóricos e práticos. Esses saberes são "oriundos da formação profissional e de saberes disciplinares, curriculares e experienciais" (TARDIF, 2002, p.36) e são adquiridos ao longo da formação inicial e continuada do professor. Os saberes experienciais devem ser considerados os mais relevantes, uma vez que, são adquiridos no âmbito do desenvolvimento da prática da docência e não se encontram sistematizados em doutrinas ou teorias educacionais (TARDIF, 2002). Mesmo assim, as instituições de formação inicial ou continuada ignoram as crenças da formação ambiental (familiar, movimentos sindicais, etc.) dos professores e insistem em apresentar suas altas teorias, esquecendo que os professores podem estar "se formando mais com os outros professores dentro das escolas do que nas aulas da universidade ou institutos de formação" (CHARLOT, 2002, p.90).

Concordando com o autor, acredito na aprendizagem contínua da docência no chão da escola a partir da partilha de experiências vividas no cotidiano escolar. Não posso ignorar as teorias estudas nos cursos de formação profissional, por outro lado, tenho que admitir que o contato com outros professores, a vivência em sala de aula e no contexto escolar, as condições objetivas de trabalho, as reflexões e discussões relacionadas aos contornos educacionais foram importantíssimos na construção da minha trajetória profissional.

A ação docente como professor substituto nos período de 2006.2 a 2008.2 e 2009.1 a 2010.2, em disciplinas do núcleo pedagógico (Fundamentos Sócio-Filosóficos da Educação; Estrutura e Funcionamento do Ensino; Currículos e Programas; Didática Educacional e Estágio Supervisionado), permitiram trabalhar nolFCE campus de Cedro, instituição federal imbuída na política nacional de formação de professores.

O curso de Licenciatura em Matemática estava nos seus primeiros anos de funcionamento com a finalidade de formar profissionais para o ensino de matemática nos anos finais do ensino fundamental (60 ao 9 Ano) e ensino médio. O desafio era contribuir para a formação docente para o ensino de matemática, motivando os licenciandos para a prática de ensino fundamentada na transformação do conhecimento matemático em conhecimento matemático escolar, uma vez que, a matemática é encarada pela maioria dos estudantes como uma disciplina de difícil compreensão.

Como professor substituto, minha maior dificuldade, consistiu em não poder se dedicar exclusivamente ao trabalho com a formação de professores, pois numa escala de prioridades, o cargo de professor efetivo na rede municipal de ensino tinha peso maior. Desta forma, a atuação no IFCE campus de Cedro se restringia ao trabalho de sala de aula, não havendo espaço para a realização de atividades de extensão e muito menos de pesquisa. 
$\mathrm{Na}$ condição de professor formador de professores, a sala de aula se configurou como um espaço construtor de aprendizagens sobre o ser e o estar na profissão docente. Estas aprendizagens foram permeadas por discussões e reflexões atinentes as ciências da educação, ao ensino e a aprendizagem da matemática e a questões didático-metodológicas, expressando experiências vividas na prática tais como: análise e estudo de recursos didáticos existentes no Laboratório de Ensino de Matemática (LEM), elaboração/construção de plano de aula, construção de oficinas de matemática, dentre outros.

Estas reflexões se tornavam mais latentes na medida em que os licenciandos se enxergavam como professores de matemática. O pensar sobre ser professor e sua função social inquietava os alunos, os quais chegavam a externar certas fragilidades vividas no curso, principalmente a fragmentação e falta de integração entre disciplinas específicas e pedagógicas; desvinculação entre teoria e prática; dificuldades de professores de ensinar matemática; aulas demasiadamente conteudistas, dentre outros, eram problemas que para os licenciandos poderia comprometer a qualidade da formação inicial de professores.

Diante das inquietações dos alunos, tivemos que refletir sobre o papel da licenciatura em matemática, que naquele momento apresentava acentuadamente, características de um bacharelado, onde a preocupação era exaustivamente o desenvolvimento e a aprendizagem do cálculo. Obviamente, poucas ou quase nenhuma mudança ocorreu. Com exceção de um professor de matemática, que em sua prática, mantinha estreita relação dos conteúdos matemáticos trabalhados com recursos existentes no Laboratório de Ensino de Matemática.

No final do ano de 2009 fui aprovado em concurso público para professor efetivo de disciplinas do núcleo pedagógico do IFCE, porém só fui convocado no início de 2011 para atuar no curso de Licenciatura em Física do campus Avançado de Tianguá, a aproximadamente 500 km da minha cidade, tendo que viajar periodicamente. Foi um período de muita dificuldade, pela distância da família, pela limitação física (Poliomielite no membro inferior esquerdo) e mobilidade reduzida. As dificuldades existem e precisam ser encaradas. Assim, acreditando na aprendizagem permanente como possibilidade de melhorar minha atuação e construção docente, iniciei o meu mestrado em Ensino de Ciências e Matemática na Universidade Federal do Ceará (UFC) em agosto de 2011e consegui apresentar a dissertação em abril de 2013.

Em outubro de 2011 por conta da minha limitação física, consegui remoção para o campus de Cedro. Estava de volta para casa e para ficar no IFCE campus de Cedro definitivamente e no regime de dedicação exclusiva podendo dedicar esforços à formação de professores de matemática, convicto de que a docência é "uma atividade profissional complexa, pois requer saberes diversificados. Isso significa reconhecer que os saberes que dão sustentação à docência exigem uma formação profissional numa perspectiva teórico e pratica" VEIGA \& D'ÁVILA (2008, p.20).

A formação do professor de matemática é um tema presente nas atividades acadêmicas que desenvolvo quotidianamente. Consciente da grandeza e da complexidade da profissão docente acredito na formação inicial como um dos passos primordiais para a melhoria da prática 
de ensino e da qualidade dos processos de ensino e aprendizagem matemática desenvolvidos na escola dos nossos tempos. Nos contornos da atual conjuntura, não é possível comportar um professor aprisionado nos limites disciplinares da sua área de conhecimento; um professor que, indiferente aos apelos do contexto social e às especificidades de sua turma, repete conteúdos, reproduz modelos e estabelece uma relação autoritária que não permite o questionamento e o diálogo.

Com base nestas questões, tento em minha prática, desenvolver o propósito da negociação, verbalizando/discutindo e conduzindo os alunos ao diálogo e a reflexão. Esta dialogicidade permite pensar sobre a docência e os fazeres da profissão, elucidando sempre que, o docente é um profissional que se defronta

[...] com a urgência, a de ser professor, e esta é uma das principais características da profissão do professor. Ser professor é defrontar-se incessantemente com a necessidade de decidir imediatamente no dia a dia da sala de aula. [...] o professor tem que decidir sem ter tempo para refletir. E, depois de decidir na urgência, ele tem que assumir as consequências da decisão, de seus atos (CHARLOT, 2002, p.91).

Assim sendo, os licenciandos acabam percebendo que o fazer docente é uma atividade que exige rumo e partilha, devendo ser entendido como prática situada e ética, cujas decisões se traduzem em uma intencionalidade que procura assegurar conhecimentos pedagógicos básicos, numa abordagem crítica e contextualizada, se assentando na necessidade de ruptura de visões fragmentadas do trabalho do professor e de assunção do papel de sujeito em seu desenvolvimento. Por isso, o professor se constitui, se reelabora, se produz, por meio das relações que estabelece com o mundo físico e social onde se encontra inserido, (re)construindo e articulando sua identidade profissional.

Pensar sobre o que fazemos e como fazemos exige reflexões constantes. Na tentativa de contribuir com a formação de futuros professores para o ensino de matemática não posso deixar de indagar sobre a importância da minha ação docente para compreender o significado do meu trabalho como professor formador de professores. Qual a relevância daquilo que eu ensino? Como estou contribuindo para a formação de futuros professores para o ensino de matemática? 0 meu fazer docente desperta nos licenciados o desejo de ser professor? Quais os impactos da minha prática na construção de identidades docentes?

Atuando em curso de Licenciatura em Matemática, tenho aprendido com os desafios da profissão, especialmente com os alunos. Penso que uma das virtudes de um professor é motivar e acreditar na capacidade pessoal e intelectual dos educandos, desafiando-os para novas aprendizagens, possibilitando a cada um a realização de diferentes leituras do espaço onde se encontra inserido. Como professor formador de futuros professores, tenho procurado pautar minhas ações em bases epistemológicas que priorizem a reflexão e a retroalimentação entre teoria e prática a partir de situações propostas no contexto da formação inicial e em experiências vividas pelos licenciados na escola de educação básica. 
Com o desejo de refletir sobre as questões apresentadas acima, procuro me lançar pelos caminhos da docência, compreendendo que os saberes construídos a partir da experiência possibilitam (re)pensar e (re)elaborar práticas pedagógicas, auxiliando no redimensionamento do fazer docente em sua ação prática. Nos encontros semanais com os licenciados no IFCE campus de Cedro, a sala de aula é concebida como um espaço multicultural que se nutre de relações podendo potencializar diferentes aprendizagens. Em sala de aula concentramos esforços para trabalhar bases teóricas da ciência da educação, as quais poderão contribuir para o desenvolvimento da prática docente que "não é apenas um objeto de saber das ciências da educação, ela é também uma atividade que mobiliza diversos saberes que podem ser chamados de pedagógicos" (TARDIF, 2002, p.37).

É em sala de aula que os licenciandos compartilham suas vivências/experiências em atividades práticas no campus de Cedro (Atividades no Laboratório de Ensino de Matemática: Planejamento de oficinas, mini-cursos, confecção e estudo de material didático;) ou em escolas municipais e estaduais dos municípios de Cedro, Várzea Alegre, Icó, Lavras da Mangabeira, Iguatú, Granjeiro, Orós, Carius, etc. (Desenvolvimento de oficinas, mini-cursos e projetos; Observação, participação e regência em sala de aula). Como expressa D’Ambrosio (1993, p.39),

[...] os futuros professores constroem seu conhecimento sobre o ensino da Matemática através de suas experiências com o ensino. Neste processo de construção, a identificação e a resolução de problemas são essenciais. Porém, se o futuro professor não tiver contato com alunos em idade escolar dificilmente poderá identificar e resolver problemas sobre ensino e aprendizagem. Daí a necessidade de incorporarmos um componente de experiência com alunos desde o início dos programas de formação de professores.

Nas atividades práticas vivenciadas nas escolas, os licenciandos em matemática, percebem que o núcleo estruturante do dia a dia escolar se constitui do currículo, dos conteúdos: ordenamento, sequenciação e hierarquias, da carga horária semanal, dos tempos e espaços escolares e das relações construídas entre alunos, professores e demais servidores. Percebem também que a disciplina de matemática, nas escolas, é encarada pela maioria dos alunos como o "bicho papão" das matrizes curriculares dos ensinos fundamental e médio.

Quando se deparam com este cenário, os futuros professores indagam sobre a situação, elencam possíveis fatores que podem ocasionar a aversão de alunos pelos conteúdos matemáticos, arriscam concluir que este é um problema antigo e que até o momento não se conseguiu alterar o quadro, por vias como, o desenvolvimento de estratégias de ensino que desperte o interesse dos educandos.

O curso de Licenciatura em Matemática como espaço de formação inicial de professores deve, em seu percurso teórico e prático, fornecer aos licenciandos subsídios que permitam trabalhar a matemática atribuindo-lhe outros significados, principalmentepossibilitar aos alunos o desenvolvimento da capacidade de resolver problemas práticos do quotidiano. No entanto, reconheço, junto com D’Ambrósio (1993) que: 
Há a necessidade de os novos professores compreenderem a Matemática como uma disciplina de investigação. Uma disciplina em que o avanço se dá como consequência do processo de investigação e resolução de problemas. Além disso, é importante que o professor entenda que a Matemática estudada deve, de alguma forma, ser útil aos alunos, ajudando-os a compreender, explicar ou organizar sua realidade. (D’AMBRÓzIO, 1993, p. 35)

A aprendizagem matemática se constitui como necessidade para se exercer com efetividade a cidadania tão falada nos últimos tempos, por isso precisa ser compreendida pelo aluno como um conhecimento útil. No decorrer da formação de futuros professores, tenho insistido que os licenciandos compreendam o ensino de matemática como um campo de investigação ${ }^{1}$, implicando pensar nos sentidos e significados que se atribui ao ensino de conteúdos matemáticos por meio de situações didáticas.

Quando o aluno não percebe utilidade naquilo que está estudando, provavelmente não enxergará relevância no seu objeto de estudo. Ao professor, cabe o desafio de apresentar aos educandos a necessidade da aprendizagem de saberes matemáticos como conhecimentos importantes que podem permitir o desenvolvimento de competências, principalmente, analisar problemas, tomar decisões e exercer melhor sua cidadania. No momento em que se traduz a naturalidade da matemática como uma condição de estar no mundo, se democratiza a possibilidade da naturalidade da matemática e isso é cidadania (FREIRE, 2007).

Hoje muitas são as demandas colocadas ao professor. Se por um lado, "espera-se dele uma atitude investigadora e crítica em relação à prática pedagógica e aos saberes historicamente produzidos; por outro lado, passa a ser responsável pela produção de seus saberes e pelo desenvolvimento curricular da escola" (FIORENTINI, SOUZA e MELO, 1998, p.332). Nesta perspectiva, o professor deve pensar sobre seu fazer, refletir e analisar sobre o que tem feito e faz em relação aos efeitos da sua prática de ensino na formação dos alunos, seu compromisso com a escola e com a sociedade.

Nestes termos "a chave da competência profissional é a capacidade de equacionar e resolver problemas da prática [...] É preciso estudo, trabalho, pesquisa para renovar e, sobretudo, reflexão para não ensinar apenas 'o que' e 'como' Ihe foi ensinado" (PEREZ, 2005, p.252).

É obrigação do formador de professores colocar como preocupação central de seu programa as questões políticas e sociais, procurando levar os futuros professores a pensar sobre essas dimensões que afetam o seu cotidiano, a sua prática de ensino, e mostrar que podem tomar decisões que estarão servindo para deixar as coisas como estão ou mudá-las. Trata-se de ter consciência de que decisões aparentemente corriqueiras fazem parte de uma rede de sustentação da permanência das desigualdades e injustiças sociais ou situam-se em outra rede,

\footnotetext{
${ }^{1}$ Nos últimos anos, alunos do curso de Licenciatura em Matemática do IFCE campus de Cedro tiveram oportunidade de aprovar e apresentar trabalhos/experiências em congressos regionais (I Simpósio Técnico do IFCE campus Cedro, 2012; Encontro de Iniciação Científica da UNIFOR: Fortaleza, 2012 e 2013) nacionais (Congresso Norte e Nordeste de Educação, Pesquisa e Inovação - CONNEP: Tocantins, 2012 e Bahia, 2013) e internacionais (VII Congresso Iberoamericano de Educação Matemática - VII CIBEM: Uruguai, 2013).
} 
aquela da luta pela mudança (ZEICHNER, 1994 apud GERALDI, MESSIAS \& GUERRA, 1998, p.264).

A partir da minha prática cotidiana, tenho proposto momentos de estudos, discussões e reflexões sobre o trabalho docente e seus condicionantes, destacando a importância do trabalho docente em uma sociedade desigual e a aprendizagem contínua como alternativa para continuar aprendendo a docência como campo de aprendizagem e de atuação profissional. Como bem expressa Lorenzato (2006) a falta de reflexão do professor sobre sua prática pedagógica pode garantir a repetição de um ensino destituído de significado para os alunos. Assim, ser reflexivo é uma exigência ao professor que persegue uma melhor postura profissional.

Para assumir melhor postura, é preciso reflexão sobre as aulas dadas e constante atualização para a formação. Na prática o que se almeja é a formação de um professor de matemática capaz de realizar diferentes leituras relacionadas à disciplina e ao seu campo de atuação, pois quando falamos de ensino e aprendizagem precisamos compreender as relações que se estabelecem entre quem ensina e quem aprende o saber matemático.

Portanto, se nas universidades e outras instituições de ensino superior os formadores de professores (Núcleo de disciplinas especificas e de formação docente) continuarem trabalhando na perspectiva da racionalidade técnica, dificilmente se formará um professor capaz de refletir e pesquisar sobre sua própria ação docente. É na formação inicial que se deve propiciar aos futuros professores a abordagem da racionalidade prática, onde o espaço de ação é também espaço de aprendizagem contínua da docência.

\section{CONSIDERAÇÕES FINAIS}

Este trabalho teve como intenção apresentar algumas reflexões sobre contextos vividos e narrativas que contribuíram para o delineamento da (re)construção da identidade de um professor formador. Olhar a própria essência e fazer esta reflexão exigiu da memória o resgate de arquivos pessoais para rever caminhos percorridos, desafios enfrentados e conquistas realizadas, que me tornam professor e constitui minha vida profissional.

Muitos são os saberes que se necessita para desenvolver o ofício de professor. Assim, o fazer docente se sustenta em conhecimentos científicos, advindos de diferentes fontes, sendo permeado por saberes da ação, que são adquiridos a partir de experiências de trabalho vividas em diferentes espaços no exercício da docência.

Com este resgate, foi possível destacar concepções de ensino e condicionantes que influenciaram o ser e o fazer docente a partir de reflexões acerca da postura do educador, como agente de transmissão e construção de saberes. Referenciar-se a nossa ação docente como professor formador é desafiador, pois acabamos percebendo a necessidade (re)pensar o saberfazer pedagógico a partir de experiências de formação e profissionalização, principalmente o ensinar e aprender com as práticas pedagógicas. 
Neste sentido, o professor formador de professores deve trabalhar na perspectiva da racionalidade prática, partindo da análise da prática docente para compreender os mecanismos e dispositivos mobilizados pelo professor durante sua ação profissional, o qual obterá êxito, conforme sua capacidade para conduzir a complexidade existente no processo e resolver problemas práticos, por meio da integração entre conhecimento e técnica.

Portanto, o professor pesquisador e reflexivo (ZEICHNER, 1993; CONTRERAS, 2002; SCHNETZLER, 2000), é aquele com conhecimento para refletir e analisar sobre o que está fazendo, preocupando-se em analisar atentamente o que faz, por que o faz e como pode transformar o que faz, experimentando novas alternativas e (re)construindo-se continuamente.

\section{REFERÊNCIAS}

Brasil, Ministério da Educação. (1971) Lei de Diretrizes e Bases da Educação Nacional. Lei no. 5.692, de 11 de agosto de 1971. Brasília; Ministério da Educação. Disponível em: http://www.planalto.gov.br/ccivil_03/leis/15692.htm. Acesso em: 30 Maio 2014.

Charlot, B. (2002) Formação de professores: a pesquisa e a política educacional. In Pimenta, S. G. e Ghedin, E. (Orgs). Professor reflexivo no Brasil: gênese e crítica de um conceito. São Paulo: Cortez.

Contreras, J. (2002) A autonomia dos professores. São Paulo: Cortez.

D’Ambrosio, B. (1993) Formação de professores de matemática para o século XXI: o grande desafio. Revista Pro-Posições, UNICAMP, São Paulo, mar.

Fiorentini, D.; Souza Júnior, A. J.; Melo, G. F. A. (1998) Saberes docentes: um desafio para acadêmicos e práticos. In: Geraldi, C.; Fiorentini, D.; Pereira, E. (Org.) Cartografias do trabalho docente: professor(a)-pesquisador(a). Campinas: Mercado das Letras.

Freire, P. (1996) Pedagogia da autonomia: saberes necessários à prática educativa. Rio de janeiro, Paz e Terra.

Freire, P. (2007) Entrevista Paulo Freire e Ubiratan D’Ambrósio. Disponível em http://nonio.fc.ul.pt/rvcc/matematica/entrevista.doc. Acesso em: 04 jun. 2014.

Geraldi, C. M. G., Messias, M. G. M. e Guera, M. D. S. (1998) Refletindo com Zeichner: um encontro orientado por preocupações políticas, teóricas e epistemológicas. In Geraldi, C. M. G., Fiorentini, D. e Pereira, E. M. A. (Orgs) Cartografias do trabalho docente: professor(a)pesquisador(a). Campinas: Mercado das Letras.

Gómez, A. P. (1992) O pensamento prático do professor: A formação do professor como profissional reflexivo. In Nóvoa, A. (Org.) Os professores e a sua formação. Lisboa: Dom Quixote.

Lorenzato, S. (2006) Para aprender matemática. Campinas, SP: Autores Associados.

Perez, G. (2005) Prática reflexiva do professor de matemática. In: Bicudo, M. A. V. e Borba, M. C. (Org.). Educação matemática, pesquisa em movimento. São Paulo: Cortez. 
Sacristán, J. G. (2002) Tendências investigativas na formação de professores. In Pimenta, S. G. \& Ghedin, E. (Orgs). Professor reflexivo no Brasil: gênese e crítica de um conceito. São Paulo: Cortez.

Schnetzler, R. P. (2000) O professor de ciências: Problemas e tendências de sua formação. In Schnetzler, R. P. e Aragão, R. M. R. Ensino de ciências: Fundamentos e abordagens. Campinas, SP: CAPES/UNICAMP.

Tardif. M. (2002) Saberes docentes e formação profissional. Petrópolis: Vozes.

Veiga, I. P. \& D’Ávila, C. (2008) Profissão docente: novos sentidos, novas perspectivas. Campinas: Papirus.

Young, M. (2007) Para que servem as escolas? Educação \& Sociedade, vol. 28, no 101, p. 1287-102, set/dez.

Zeichner, K. M. (1993) O professor como prático reflexivo. In: Zeichner, K. M. A formação reflexiva de professores: ideias e práticas. Lisboa: Educa. 